\title{
O NÃO LUGAR DA AURA NA REPRODUTIBILIDADE TÉCNICA DA ARTE
}

Raquel Rodrigues Rocha

\begin{abstract}
"Não se trata, porém, de teses sobre a arte do proletariado após a tomada do poder e muito menos sobre a arte em uma sociedade sem classes, mas sobre 0 desenvolvimento das artes nas atuais condições de produção."
\end{abstract}

Walter Benjamin

\section{RESUMO}

O advento da reprodutibilidade técnica da arte, como rádio, a fotografia e o cinema, resulta na destituição do lugar da aura na obra de arte. A partir de tal premissa, a análise da estética - à medida em que a sociedade se transforma, quer no processo de produção, quer na forma como a arte passa a ser percebida e utilizada pelos homens, com o advento de uma nova mentalidade movida pela "tecnologização" - irá revelar a interface política da obra de arte e sua função na sociedade da reprodutibilidade.

Palavras-Chave: Aura. Reprodutibilidade. Arte. Benjamin

\section{THE NON-PLACE OF AURA IN REPRODUCTABILITY TECHNICAL ART}

\begin{abstract}
The advent of mechanical reproduction of art, such as radio, photography and film, results in the dismissal of the place of aura in the work of art. From this premise, an analysis of aesthetics - the extent to which society is transforming, is not a production process, as a form as an art comes to be perceived and used by men, with a new mindset driven by "Technology" - to reveal a political interface of the work of art and it is within the reproduction society.
\end{abstract}

Key-words: Aura. Reproducibility. Art. Benjamin 
Sob uma perspectiva muito mais crítica que entusiasta das novas formas de arte, Benjamin nos mostra como a relação entre espectador, artista e obra é modificada com a possibilidade de reprodutibilidade técnica da arte e também dos seus novos meios de produção, em especial a fotografia e o cinema. É no jogo de valores positivos e negativos dos meios de produção e reprodução que podemos perceber como a obra de arte, a partir do século XIX, gradativamente perde o seu valor no que diz respeito aos conceitos tradicionais de genialidade, originalidade e culto. E, ao ser destituída desses valores tradicionais, é resignificada como um meio de resistência política e possibilidade de auto alienação das grandes massas. Pois, a reprodução em massa da obra de arte conduz a uma nova percepção tanto do sentido da arte, quanto da história, isto é, a ressignificação da arte na era industrial, promove sua atualização ao mesmo tempo em que nela empalidece a aura - seu valor de eternidade.

Ao empreender uma análise acerca da obra de arte no século XIX e XX percebe-se, logo de início, que a intenção de Benjamin é abordar a obra de arte a partir de seu potencial revolucionário de mudanças e não a partir de uma dialética do materialismo. Os novos meios de produção e reprodução destacados pelo autor, trazem consigo uma nova percepção da arte como meio de uma função política e de resistência. No entanto, esse tipo de arte como resistência difundido via os meios de comunicação ${ }^{1}$ torna-se largamente reproduzida, provoca o declínio do valor de culto e autenticidade presentes na aura, na qual a obra de arte estaria envolta. Não podemos deixar de considerar aqui que um dos motivos dessa perda da aura é relação entre a produção de arte e os meios de comunicação pelos quais a arte torna-se popular e acessível. Ora, ao surgirem, os meios de comunicação transformam a relação dos homens com a arte e principalmente com o modo de fazer arte e seu significado. É nessa transformação que buscaremos compreender porque não há um lugar central da aura em meio à reprodutibilidade técnica.

Como podemos observar no texto em questão, embora desde seu início, a arte tenha por característica a possibilidade de reprodutibilidade, é nos séculos XIX e XX que tal característica aparece com mais força, pois a criação de novas técnicas de reprodução e difusão da arte altera diretamente a forma

\footnotetext{
${ }^{1}$ Rádio, cinema, fotografia (nos jornais e folhetins).
} 
como o homem se relaciona com a obra de arte. Os surgimentos da fotografia, do rádio, do cinema promovem uma maior aproximação entre o espectador e a obra. Assim, mais que uma experiência do belo, a arte se torna uma experiência estética capaz de promover e contribuir ativamente nas transformações sociais de sua época. Tanto a fotografia quanto o cinema ocupam um lugar especial na reprodutibilidade da arte, pois ampliam a percepção dos homens e influenciam na mudança de percepção política e social, ao mesmo tempo em que liquidam o valor de tradição da obra de arte. Nas palavras de Benjamin: Formulado de modo geral, a técnica reprodutiva desliga o reproduzido do campo da tradição. Ao multiplicar a reprodução, ela substitui sua existência única por uma existência massiva. (BENJAMIN, 2013, 55)

No que diz respeito à fotografia, esta é caracterizada como importante meio de reprodutibilidade técnica por facilitar a reprodução da arte. Seu processo mecânico de captura da imagem por meio de uma lente acelera a reprodução da arte. Para reproduzir uma imagem não é mais preciso o trabalho manual de cópia, como acontece com as litografias e pinturas. Com isso temos a primeira transformação provocada pela reprodução técnica, a saber: a reprodutibilidade técnica altera a relação do homem com a obra de arte e a tradição. Reproduzida em larga escala, a arte torna-se mais acessível às massas, e adquire um novo significado no qual não cabe mais uma percepção de aura da própria obra. A grosso modo, podemos admitir que o processo de aproximação entre espectador e arte é também o processo que promove uma perda da aura: "Mesmo na reprodução mais perfeita uma coisa se perde: o aqui e agora da obra de arte, sua existência única no local em que se encontra. No entanto, é nessa existência única, e somente nela, que está realizada a história à qual a obra de arte esteve submetida no decorrer de sua duração. " (Ibidem. 63-64)

Ora, se o conceito de originalidade da obra é composto por seu caráter de aqui e agora, a reprodutibilidade por meio da técnica mecânica faz com que a originalidade da obra seja diluída em meio a reprodução de massa da arte. $O$ importante para a arte não é mais a sua aura, seu caráter de exclusividade, o valor único e sim sua finalidade enquanto agente de transformação. Há, portanto, um declínio que pode ser compreendido como sinal da perda do lugar 
da aura em relação ao seu valor dentro da arte. Daí afirmarmos que reprodutibilidade técnica, afasta aquilo que foi produzido do campo da tradição, substituindo uma produção única por algo massificado. Nesse sentido, a massificação da arte ao mesmo tempo em que atua como auto alienação também possui certo caráter revolucionário. Uma fotografia, uma música, um filme por exemplo, ao serem reproduzidos em larga escala perdem seu valor de aqui e agora, seu valor de culto, pois o lugar da aura é substituído pelo caráter de possibilidade de transformação político-social.

Vale destacar que Benjamin estabelece uma comparação entre cinema, fotografia teatro e literatura para apresentar como a evolução da obra de arte em seu caráter de reprodutibilidade faz com que haja um desaparecimento da aura. Com isso o autor elabora uma crítica à massificação e alienação promovida a partir da arte como ferramenta de engajamento político. Portanto, é importante que não dissociemos a evolução da produção de obra arte das mudanças culturais e nem do contexto das revoluções sócio econômicas nos séculos XIX e XX.

Em outro texto, Sobre alguns motivos na obra de Baudelaire, Benjamin destaca ainda a relação entre fotografia e a memória voluntária do homem, explicando assim como a fotografia contribui para a perda da imaginação humana, pois ao ativar a memória já acabada nela mesma, a fotografia não deixa margem para que se imagine além daquela memória ativada. Por provocar um tipo de memória sempre disponível ao homem, a fotografia faz com que a imaginação do expectador seja reduzida e se esgote em si mesma. Para o autor, “ A constante disponibilidade da lembrança voluntária discursiva favorecida pelas técnicas de reprodução, reduz o âmbito da imaginação. (BENJAMIN, 1989, 139). Essa nova relação estabelecida entre o homem, arte e a memória provoca um enfraquecimento da aura, pois a imediaticidade e disponibilidade que a reprodução da fotografia dispõe aos espectadores faz com que o caráter de autenticidade e valor de culto da arte sejam perdidos. Mais uma vez, Benjamin demonstra que é na autenticidade da obra de arte que reside o lugar da sua aura, no despertar provocado pelo caráter aqui e agora, este despertar não tem força de significado na massificação da arte.

Embora a reprodução técnica faça com que a arte perca sua característica de aqui e agora, ela possibilita alguns aspectos positivos para 
análise da obra de arte, por exemplo: as lentes da câmera podem revelar ângulos e alguns pontos da imagem que são imperceptíveis a olho nu, além da possibilidade de permitir um maior acesso às obras clássicas e sacrossantas por meio da reprodução sob a forma de fotografia, promovendo assim uma aproximação e disseminação da arte para o maior número possível de pessoas. Muito embora a reprodutibilidade provoque uma perda do lugar da aura na obra de arte, ela - a reprodutibilidade - conserva seu conteúdo e o atualiza, substituindo uma existência autêntica da arte por uma existência social, ressignificando o sentido da arte para as massas. Daí inferirmos que arte é atualizada em seu significado e finalidade na medida em que é reproduzida e de acordo com a exigência dos movimentos de massa. É em meio ao processo de massificação e esgotamento da arte que podemos então perceber a aura sendo destituída de seu lugar de privilégio na arte. A aura é relegada diante da nova percepção das massas e dos novos movimentos artísticos.

Dentro dessa relação entre perda da aura, reprodutibilidade técnica e atualização a arte e crítica à massificação, Benjamin apresenta o cinema como um meio mais poderoso de controle das massas. Acerca do cinema como meio de massificação, o autor nos diz:

\footnotetext{
Seu significado social, também em sua forma mais positiva, não é compreensível sem o seu lado destrutivo, catártico: a liquidação do seu valor tradicional no patrimônio cultural. Esse fenômeno é particularmente perceptível nos grandes filmes históricos. (BENJAMIN, 2012, 13)
}

É fundamental reafirmarmos aqui o papel da arte e sua história no contexto social do qual ela está inserida. Pois a percepção da arte muda de acordo com o período histórico vivido, não havendo como dissociar a arte produzida de seu período histórico e nem da percepção do homem em seu tempo. Convém ressaltar, portanto, a relação entre as transformações históricas, o homem e a arte. A coletividade das massas, principalmente no século $X X$, demanda um tipo de arte que se adeque as suas questões, a realidade vigente. A percepção da história feita sob a ótica das imagens (fotografia e cinema) é a que melhor se adequa à demanda da coletividade. A arte tradicional com seu valor de culto e sua aura não possui importância para 
a finalidade da arte como meio de revolução e ou alienação. O que interessa ao homem é uma aproximação da arte em seu potencial revolucionário e ou de distração das massas, o que justifica assim, o não interesse dos homens (pós revolução do proletariado) por um tipo de arte para contemplação, arte estática envolta em sua aura de mistério e culto e valorizada por seu caráter de autenticidade. Com a reprodutibilidade técnica, a percepção do espectador é direcionada para uma arte que provoque uma sensação de pertencimento a uma coletividade, em outras palavras, uma arte voltada para seu caráter revolucionário ou de distração das massas.

Nesse sentido, encontramos o declínio da aura associado à maior aproximação da obra de arte com o espectador e esse novo modo de perceber a arte provocado pela reprodutibilidade técnica. De acordo com Benjamin, há dois motivos que podem ser apontados como condicionantes do desaparecimento da aura, a saber: o desejo de aproximação despertado pelas grandes massas, espacial e humanamente, das coisas e o desejo de superar 0 caráter único das coisas, isto é, superar a própria aura. Assim, é o próprio desejo de aproximação da arte, a partir da reprodução técnica da imagem, que faz com que a massa destitua a aura de seu lugar na arte. Como o autor afirma: "Despojar o objeto do seu invólucro, destruir sua aura, esta é a característica de uma percepção cujo "sentido semelhante no mundo" é tão forte que captura o singular por meio da reprodução. " (BENJAMIN, 1985, 14$15)$.

Sabendo que a arte e seu valor está associado ao momento histórico no qual ela faz parte, podemos então compreender que a autenticidade da obra de arte e seu sentido estão relacionados a uma tradição mutável da percepção e atualização histórica da arte e das revoluções. O valor de culto da arte, num primeiro momento, é relacionado à tradição religiosa, ao ritual. Com o passar do tempo tal valor de culto relaciona-se também com 0 caráter de exclusividade, unicidade. Porém, com o advento da fotografia, esse valor de culto relativo a unicidade da obra é posto em questão.

Em contrapartida à revolução provocada pela fotografia e sua aproximação com o ideal socialista, cria-se a ideia de uma arte pela arte. Tal ideal recusa a concepção de uma função social da arte, frente à perspectiva de uma arte pura, que tenta descaracterizar a evidente influência da reprodução 
da arte no contexto social da época. Todavia, a reprodução em larga escala emancipa a arte do conceito de arte pela arte - que Benjamin considera uma teologia da arte - tornando-a objeto de reprodução e não mais objeto de culto ou desligado de uma função social. Desse modo, a obra de arte é inserida na práxis política. Assim, é possível inferir que a destituição da aura dá lugar a uma ideia de arte como meio de engajamento político, o critério de autenticidade da arte não tem mais valor para produção artística. Com a reprodução, o que acontece no cinema, a arte revela outra interface - a possibilidade de uma práxis política.

Temos aqui duas funções distintas da obra de arte: o valor de culto e o valor de exposição. $\mathrm{Na}$ medida em que a emancipação da obra de arte a distância da aura, o valor de culto dá lugar ao valor de exposição, em outras palavras, seu valor cultural é relegado a um plano secundário em função do aparecimento de um outro valor - o de exposição da arte - possível a partir de sua reprodutibilidade técnica. No entanto ainda se encontra, nas técnicas de reprodução, uma atualização de valor de culto da arte presente na forma de retrato fotográfico. Nesse tipo de fotografia ainda é possível encontrar um resquício do valor de culto que resiste à perda total da aura. Assim, é na recordação provocada pela foto da pessoa amada ou entes falecidos que a aura ainda encontra um lugar de refúgio. É apenas quando o retrato humano dá lugar às paisagens que a aura perde totalmente seu lugar na reprodução da arte, agora é a fotografia de uma paisagem de campo, cidade ou até mesmo de cenas de crime que se torna testemunha da história.

A fotografia, assim como o cinema, possui um valor político importante pois ao induzirem o espectador no caminho da interpretação da arte, tais formas de arte admitem uma postura sócio-política que influencia os espectadores. Elas direcionam as opiniões de classes, conduzem as massas a agir a partir de determinado padrão social. Ante tal afirmação, percebe-se que a perda da aura promove também uma perda da autonomia da arte, não é mais possível uma arte ter valor se ela não possui uma finalidade social. ${ }^{2}$ Mas esse

\footnotetext{
${ }^{2}$ Não podemos esquecer aqui que a relação entre arte e transformação social é bilateral, isto é, ao mesmo tempo em que a arte muda a percepção das massas, elas também se adaptam as evoluções sociais e se adaptam as necessidades de mudanças demandadas pelas grandes massas.
} 
fim, a arte o matem enquanto arte, e não ao assumir uma intencionalidade. A arte não tem intenção. O conteúdo de verdade (Wahrheitsgehalt) da arte não comporta nenhuma intenção. Ela deriva do inconsciente. A arte educa enquanto arte, por conter a totalidade do humano. Se o artista está passando por um momento angustiante, sua arte acaba exalando, inconscientemente, esse conteúdo anímico.

Quanto ao cinema, Benjamin afirma que a relação estabelecida entre ator e plateia é diferente da que é estabelecida no teatro, primeiro porque no cinema há o intermédio da máquina entre ator e público e em segundo lugar porque é estabelecida uma relação fabril entre 0 ator $e$ a indústria cinematográfica. O teatro assim como o retrato, ainda mantém certa aura em sua apresentação, ao passo que, no cinema, essa aura só sobrevive na relação do ator com seu estrelado, visto que na relação entre ator e público, feita por meio da máquina de projeção e das câmeras, a aura desaparece. 0 ator de cinema é ciente de que a relação estabelecida com seu público é uma relação mercadológica: ele vende sua força de trabalho para um público de consumidores, e sob tal perspectiva também não permanece nenhuma aura na obra do ator.

Temos aqui dois tipos de relação estabelecidas pelos atores, a primeira configura uma relação mercantil com a indústria cinematográfica e o público como consumidores e na segunda se define a relação do ator com o estrelato. Nesta última, há uma recriação do valor de culto ao mesmo tempo em que a reprodução técnica vincula-se à ideia de consumo da arte, pois o ator é tido como mercadoria. Neste caso, a aura só sobrevive na persona das grandes estrelas de cinema. Tal como o culto à personalidade criado pela indústria hollywoodiana, a aura é recriada para que a ideia de estrelato sobreviva.

Tal como afirmamos mais acima, a indústria cinematográfica, assim como a indústria fotográfica, figura num meio eficaz de manipulação e disseminação de ideologias e também de controle de massas. Enquanto a relação entre espectador e arte acontece com certo distanciamento como por exemplo no caso da pintura, no cinema há uma aproximação entre o espectador e a arte. Na medida em que o espectador se aproxima da arte, ele 
assume para si certo caráter crítico ante aquilo que lhe é apresentado. É justamente nesse viés crítico, proporcionado pela aproximação da arte, que o cinema é considerado um indicador social importante para o controle das massas. Ele dá aos indivíduos uma noção de coletividade, um sentimento de pertencimento a uma massa. Ao sentir-se como parte de algo, os indivíduos tornam-se passíveis de serem controlados.

O controle das massas através do cinema é possível porque na arte cinematográfica há uma ampliação da capacidade de percepção das coisas e da realidade do mundo ao mesmo tempo em que não permite uma fruição livre do pensamento. Isto porque a rapidez das imagens na tela do cinema condiciona o pensamento, não deixa tempo para que o espetador se deixe levar pela contemplação, tal como é possível fazer com a pintura e a fotografia. Nesse contexto, o cinema tem por função distrair as massas. As imagens, as histórias desenvolvidas nos filmes conduzem o público a absorver a mensagem transmitida pela narrativa facilitando a manipulação de opinião e conduta das grandes massas. Tal característica do cinema justifica o porquê de os regimes totalitaristas usarem o cinema como meio de controle da população e disseminação de seus ideais.

Em contrapartida ao caráter social do cinema, temos o movimento dadaísta e sua reativação do conceito de arte pela arte, de arte sem finalidade social ou comercial. O dadaísmo desprende-se totalmente do valor comercial de produção da arte e de seu valor enquanto agente social de mudança. Segundo o autor, "As manifestações dadaístas eram capazes de distrair profundamente, na medida em que transformavam a obra de arte em objeto de escândalo. Seu primeiro objetivo era, sobretudo, provocar a indignação pública. " (Ibidem, 29).

É possível perceber que o cinema, em sua superficialidade, proporciona a distração que as massas exigem. Quanto mais o cinema é usado como meio de distração, mais a aura perde seu lugar na obra de arte, visto que o espectador não deseja recolher-se absorto no filme ou percebe o cinema como objeto culto, como faz com a pintura. Podemos compreender melhor essa relação do cinema com as massas ao considerarmos que a relação entre a obre de arte cinematográfica e o homem se dá por meio da percepção tátil e óptica e não por meio da contemplação. As grandes mudanças sociais 
observadas no século XX se dão por meio da recepção tátil e do costume. É no costume, ao qual as massas estão propensas, que reside o perigo da alienação, visto que as massas percebem o cinema como meio de distração de suas ocupações diárias.

É imerso nesse contexto de perda do lugar da aura na obra de arte que Benjamin nos apresenta a relação entre a arte contemporânea reproduzida (exemplificada no cinema, no rádio e na fotografia) e o fortalecimento do fascismo. Para o autor, o fascismo, ao tentar organizar as massas recém surgidas, propõe uma estetização da política, usa a arte como instrumento de controle das massas, ação esta que culminou na guerra e no uso da estética chamada de arte pela arte que tem a arte como finalidade em si mesma. Benjamin indica que a saída para a estetização política proposta pelo fascismo está na própria arte, na sua interface revolucionária. E assim ele diz que os comunistas respondem ao fenômeno fascista de estetização da política com a politização da arte.

Ante tais considerações, podemos concluir que é justamente onde a arte torna-se objeto de distração e alienação que o seu valor de culto $e$ autenticidade são perdidos. A aura não mais possui um lugar determinante e estabelecido na arte. Numa sociedade onde o consumidor, o público busca a arte como meio de distração, não há lugar para uma arte que promove a fruição do pensamento, a contemplação, o culto.

\section{REFERÊNCIAS}

ABREU, Wesley Carlos. "Benjamin e Adorno: um debate sobre a Arte no século XX” in: - Cadernos Walter Benjamin, № 11, Jul-Dez, 2013 acessível em: http://www.gewebe.com.br.

BENJAMIN, Walter. A obra de arte na era da reprodutibilidade técnica. L\&PM Editores, 2013.

Brasiliense, 2012.

Obras escolhidas I. Magia e técnica, arte e política. 
Obras escolhidas III. Charles Baudelaire um lírico no auge do capitalismo. Brasiliense, 1989.

Baudelaire e a Modernidade. Autêntica Editora, 2015.

OLIVEIRA, Emanuelle Beserra. "A destruição da Aura e o Entkunstung da arte como resultado da reprodutibilidade técnica" in: Cadernos Walter Benjamin, № 15, Jul-Dez, 2015 acessível em: http://www.gewebe.com.br

PEIXOTO, Enock da Silva. "Reflexões sobre a influência da tecnologia na vida atual a partir do livro $A$ obra de arte na era da sua reprodutibilidade técnica de Walter Benjamin" in: Cadernos Walter Benjamin, № 16, Jan-Jun, 2016 acessível em: http://www.gewebe.com.br 